\title{
Formulation Development and Evaluation of Anti-inflammatory Potential of Cordia obliqua Topical Gel on Animal Model
}

\author{
Richa Gupta ${ }^{1 *}$, Ghanshyam Das Gupta²
}

\section{Richa Gupta ${ }^{*}$, Ghanshy-} am Das Gupta ${ }^{2}$

'Assistant Professor, Department of Pharmacognosy, ASBASJSM College of Pharmacy, Bela (Ropar), 140111, Punjab and PhD scholar of IK Gujral Punjab Technical University, Jalandhar, Punjab, INDIA.

2Director \& Professor, Department of Pharmaceutics, ISF College of Pharmacy, Ghal Kalan, Ferozpur G. T. road, Moga, 142001, Punjab, INDIA.

\section{Correspondence}

\section{Richa Gupta}

Assistant Professor, Department of Pharmacognosy, ASBASJSM College of Pharmacy, Bela (Ropar), 140111, Punjab, INDIA.

Phone No: +91-9041393001

E-mail: rgcognosy@gmail.com

\section{History}

- Submission Date: 04-10-2017;

- Review completed: 02-11-2017;

- Accepted Date: 08-11-2017

\section{DOI : 10.5530/pj.2017.6s.163}

\section{Article Available online}

http://www.phcogj.com/v9/i6s

\section{Copyright}

(C) 2017 Phcog.Net. This is an openaccess article distributed under the terms of the Creative Commons Attribution 4.0 International license.

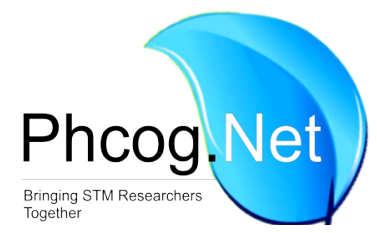

\begin{abstract}
Background: The plants of genus Cordia has been used in traditional medicine for many diseases from history. Cordia obliqua Willd. is also a medicinally important plant and it has been proved by modern scientific research. Objective: This study is aimed to formulate and characterize a topical gel from Cordia obliqua leaf methanol extract and evaluate its effect on carrageenan induced rat paw edema. Materials and Methods: The methanol extract was prepared by successive solvent extraction using soxhlet apparatus. Topical gel was designed to prepare by Dispersion method using Carbopol 940 as polymer. The various gel characteristics was studied by standard procedures like Homogeneity, grittiness, extrudability, drug content, spread ability and in-vitro diffusion study. The anti-inflammatory potential of gel was evaluated by Carrageenan induced rat paw edema method in comparison with standard Diclofenac Sodium gel $1 \%$ on Albino rats. Results: The herbal gel was found homogeneous with good extrudability, no grittiness, pH 6.79 and drug content 93.167\%. The anti-inflammatory activity of herbal gel was found comparable with standard Diclofenac Sodium gel and has shown $82.71 \%$ edema inhibition after $4 \mathrm{~h}$ of treatment. Conclusion: Cordia obliqua gel was found suitable as a standard topical gel formulation and it can be used safely for treatment of edema.
\end{abstract}

Key words: Carbopol 940, Carrageenan induced edema, Cordia, in-vitro diffusion, Topical gel.

\section{INTRODUCTION}

The drug delivery by topical route is a convenient way for both local and systemic treatment. The topical gel is a localized system for drug delivery anywhere in the body via skin, rectal, ophthalmic and vaginal routes. Skin is the most extensive and easily accessible organ for topical drug administration and gel formulation are stable and provides better absorption and bioavailability of drug as compared to other topical route formulations. ${ }^{1}$

The Cordia obliqua plant (Common name- Clammy Cherry and Lasora, Family- Boraginaceae) is a well distributed, medium-sized tree of vigorous growth. It possesses various medicinal activities as per traditional system and some of them have been proven by modern research. ${ }^{2}$ In our previous study, we have done phytochemical study and evaluated analgesic, antipyretic and anti-inflammatory activities of Cordia obliqua leaf methanol extract. It was found rich in phenolics, flavonoids, alkaloids, Glycosides and steroids with good antioxidant effect as compared to other extracts of leaf. ${ }^{3}$ It has also shown highly significant analgesic, antipyretic and anti-inflammatory activity. Before evaluation of activities, the maximum safe dose of leaf extract was also determined as $2000 \mathrm{mg} / \mathrm{Kg}$ by acute oral toxicity study. ${ }^{4}$ So the leaf extract was selected for topical gel formulation. The objective of this study was to formulate a topical gel of Cordia obliqua leaf methanol extract, study the various physicochemical parameters of gel and evaluate the potential against Carrageenan induced rat paw edema.

\section{MATERIALS AND METHODS}

\section{Plant material}

The leaves of Cordia obliqua Willd. were collected from Jammu and authenticated by Dr. (Mrs) Sunita Garg, Chief Scientist, Raw Material Herbarium and Museum (RHMD), Council of Scientific and Industrial Research-National Institute of Science and Information Resources (CSIR-NISCAIR), New Delhi, with the reference no. NISCAIR/RHMD/Consult/-2014/2383-163. A leaf sample was submitted in Pharmacognosy department herbarium of ASBASJSM College of pharmacy, Bela (Ropar) for future reference.

\section{Chemicals and instruments required \\ Carbopol 940 polymer, Methyl Paraben, Propyl Paraben, Propylene Glycol 400, Triethanoamine (TEA) and all solvents were purchased from Loba Chemie Pvt. Ltd. Mumbai, India. Carageenan was purchased from Himedia (Mumbai). Various instru- ments used were Brookfield Viscometer (Model no. LVDVE230), $\mathrm{pH}$ meter of Control Dynamis,}


Diffusion cell apparatus of Orchid Scientificus and UV-Visible spectrophotometer (Pharma Spec UV-1700) from Shimadzu, Motic photomicroscope and Bruker's FT-IR spectrophotometer.

\section{Extraction method}

About $1 \mathrm{Kg}$ of crude leaf drug was dried in shade and coarsely powdered. The extraction process of leaf powder was carried out using soxhlet apparatus and solvents for extraction were used in order of increasing polarity (Hexane, Chloroform, Methanol and water) to extract all phytoconstituents. Then all the four extracts were separately concentrated using Rotary vacuum evaporator and kept in desiccator. The methanol extract yield was determined as $1.2 \% \mathrm{w} / \mathrm{w}$ and it was non-sticky and of dark Green color. According to previous study results, methanol extract was found rich in Phyto-constituents with better antioxidant effect in comparison to other extracts of leaf. ${ }^{3}$ It has also shown good impact in treatment of pain, edema and fever conditions. ${ }^{4}$ So leaf methanol extract was selected for formulation of topical gel.

\section{Method of preparation for gel}

For topical gel preparation, Dispersion method was used because Carbopol polymers can be easily dispersed in water by stirring at room temperature. All the ingredients were accurately weighed Table 1 . Then Carbopol 940 was dispersed in $50 \mathrm{ml}$ of distilled water with constant stirring. Methyl Paraben and Propyl Paraben were dissolved separately in $5 \mathrm{ml}$ of distilled water by heating on water bath. The solution was cooled and then added Propylene Glycol 400. After this leaf extract was added and then this solution was mixed in solution of Carbopol 940 and volume was made up to $100 \mathrm{ml}$ by distilled water. Finally, sufficient quantity of Triethanolamine (TEA) was added in the mixture by continuous stirring for adjustment of required gel strength. Then weight and $\mathrm{pH}$ of gel formulation was determined. ${ }^{5,6,7}$

\section{Evaluation}

The various physico-chemical parameters studied to characterize the Cordia obliqua topical gel are following:

\section{Homogeneity}

The developed gel was tested for homogeneity by visual inspection after the gel has been set in the container. It was tested for appearance and presence of aggregates. ${ }^{8}$

\section{Grittiness}

The formulation was evaluated microscopically for the presence of particles if any. ${ }^{6}$

\section{Extrudability study}

This study of gel formulation is performed to measure the force or pressure required to extrude the gel from a tube. More quantity of gel extruded ensures the better extrudability. This method is based upon the percentage quantity of gel extruded out from collapsible tube on application of finger pressure. Aluminum collapsible tube was filled with $10 \mathrm{~g}$ of gel using universal tube filing machine and was hold between fingers. The tube was compressed by applying finger pressure and extrudability of the formulation was determined by measuring the amount of gel extruded in percentage on application of finger pressure. ${ }^{9,10,11}$

\section{Measurement of $\mathrm{pH}$}

The $\mathrm{pH}$ of formulation was determined by using digital $\mathrm{pH}$ meter. $1 \mathrm{~g}$ of gel was dissolved in $100 \mathrm{ml}$ of distilled water and stored for $2 \mathrm{~h}$. The $\mathrm{pH}$ measurement of formulation was done in triplicate and standard deviation was calculated. The $\mathrm{pH}$ of gel must be ideally near to normal $\mathrm{pH}$ of the skin to avoid any irritation. ${ }^{12}$

\section{Drug content}

$1 \mathrm{~g}$ of gel was taken and dissolved in $100 \mathrm{ml}$ of phosphate buffer $\mathrm{pH} 5.5$ in a volumetric flask. The flask was kept for $2 \mathrm{~h}$ and shaken well in a shaker to mix it properly. The solution was filtered. $1 \mathrm{ml}$ of the filtered solution was taken and diluted to $10 \mathrm{ml}$ in a $10 \mathrm{ml}$ volumetric cylinder. This solution was measured spectrophotometrically at $275.5 \mathrm{~nm}$ against phosphate buffer as blank. The drug concentration in gel was determined by comparing the absorbance of gel solution to slope of standard curve of Cordia obliqua leaf methanol extract. A drug content value gives a test of homogeneity of the gel. ${ }^{13,14}$

\section{Viscosity study}

The measurement of viscosity of the prepared gel was done with Brookfield viscometer. The gels were rotated at $2.5 \mathrm{rpm}$ using spindle no. 64 and the corresponding dial reading was noted. ${ }^{12}$

\section{Spread ability study}

One of the criteria for a gel to meet the ideal qualities is that it should possess good spread ability. It is the term expressed to denote the extent of area which gel readily spreads on application to the skin or affected part. The therapeutic efficacy of a formulation also depends upon its spread ability value.

The Spread ability of the gel was determined by measuring the spreading diameter of gel $(1 \mathrm{~g})$ between two horizontal plates of $20 \mathrm{~cm} \times 20 \mathrm{~cm}$ after one min of time. The standard weight of $125 \mathrm{~g}$ was applied on the upper plate to determine spread ability. The diameter of spreaded circle was measured in $\mathrm{cm}$ and the result obtained is average of three determinations. ${ }^{15}$

\section{Skin irritation study}

To determine effect of gel on skin, albino Wistar rats of either sex in the weight range 180-200 g was used. The entire undamaged skin was used and hairs were removed three days before the experiment. In test group, topical herbal gel was applied and in control group, gel base was applied on the back of animal. The gel was applied daily up to seven days and then the treated skin was visually examined for any type of skin irritation and score for skin irritation was assigned as 0 (no irritation), 1 (no erythema but definite dryness), 2 (Moderate erythema), 3 (moderate to severe erythema with slight edema) and 4 (moderate to severe erythema with severe edema extending beyond the marked area). ${ }^{15,16}$

\section{FT-IR spectra study}

To study any possible interaction between extract and excipients, FT-IR spectrum of both methanol extract and herbal gel formulation were taken and compared. The gel excipients should be compatible with drug extract for a formulation. ${ }^{17}$

\section{In-vitro diffusion study}

The in-vitro diffusion study of prepared gel was carried out in KesharyChein diffusion cell apparatus. In Keshary-Chein diffusion cell, 500 mg of gel was spread uniformly on the cellophane membrane which was previously soaked in phosphate buffer $\mathrm{pH} 5.5$ for $24 \mathrm{~h}$ and was sandwiched between donor and receptor compartment. $6 \mathrm{ml}$ of phosphate buffer was used as receptor compartment. The temperature was maintained at $37 \pm 0.5^{\circ} \mathrm{C}$. The whole assembly was fixed on a magnetic stirrer and the solution in the receptor compartment was constantly stirred using magnetic bead at $450 \mathrm{rpm}$. Sample of $1 \mathrm{ml}$ was withdrawn at hly interval and replacement was done with $1 \mathrm{ml}$ of fresh buffer. The drug concentration on the receptor fluid was determined spectrophotometrically against blank at $275.5 \mathrm{~nm}$. The cumulative amount of drug released expressed in \% was plotted for formulation. ${ }^{18,19,20}$ 


\section{Assessment of Anti-inflammatory activity Animals}

The Albino Wistar rats (180-200 g BW) were used for the present study. These were maintained under standard environment conditions and were feed with standard pellet diet. The animals were given a time of seven days before experiment to get acclimatized with laboratory conditions. They were deprived of from food before $18 \mathrm{~h}$ of experiment. After this they were taken for experiment. The experimental protocol was subjected to the scrutinization of Institutional Animal Ethical Committee (IAEC) of ASBASJSM College of Pharmacy, Bela and was approved under the Protocol No. ASCB/IAEC/07/14/92 and animals were kept with proper care according to the guidelines of CPCSEA, New Delhi (Regn. No. 724/ $\mathrm{PO} / \mathrm{a} / 02 / \mathrm{CPCSEA})$.

\section{Carrageenan-induced rat paw edema method}

Albino Wistar Rats were divided in three groups (six animals in each, $\mathrm{n}=6$ ) as positive control, standard treatment group and test group. The positive control group was compared with standard i.e. Diclofenac Sodium gel $1.0 \%$ (Standard group) and gel formulation of Cordia obliqua Willd. leaf methanol extract (Test group). Edema was induced by injection of Carrageenan $(0.1 \mathrm{ml}, 1 \% \mathrm{w} / \mathrm{v}$ in normal saline) into the sub-plantar tissue of the right hind paw in all groups animal. The linear paw circumference was measured using digital screw gauze. The paw circumference measurements were made before induction of edema and at hly intervals for $4 \mathrm{~h}$ after induction. No any treatment was given to control group. Both standard and test gel was applied to the sub-plantar tissue of the right hind paw of animal in $1 \mathrm{~g}$ quantity by gently rubbing with index finger for 50 times.

The percentage value of edema inhibition was calculated by the following formula-

$$
\% \text { inhibition }=1-(y-x / b-a) \times 100
$$

Where, $\mathrm{x}=$ Initial paw thickness of test group animal, $\mathrm{y}=$ Paw thickness of test group animal after treatment, a= Initial paw thickness of control group animal, $b=$ Paw thickness of control group animal after treatment. ${ }^{15,21}$

\section{Statistical analysis}

The values are expressed as the mean \pm SEM, for number of animals used $(n)=6$. The result was statistically analyzed by one-way ANOVA followed by Tukey's multiple comparison tests. The p-value $<0.05$ was statistically significant when compared with control.

\section{RESULTS}

\section{Evaluation of topical gel formulation}

The observations of various evaluation parameters for Cordia obliqua topical gel are given in Table 2. The herbal gel was found smooth, particle free and having good spread ability. The drug content in gel was determined with the help of standard curve of Cordia obliqua leaf methanol extract Table 3, Figure 1. Absorbance for gel sample $(1 \mathrm{mg} / \mathrm{ml})$ was observed 0.2103 . The drug content was calculated using straight line equation of standard curve for observed absorbance and the value was compared with theoretical amount of extract in gel formulation using the following formula-

Percentage drug content $=($ Calculated concentration of extract in gel by standard curve / Theoretical concentration of extract in gel by formula) $\times 100$

The drug content in gel formulation was determined as $93.167 \% \mathrm{w} / \mathrm{w}$. No any type of skin erythema and irritation was observed after application of Cordia obliqua topical gel formulation for seven days. It ensured that this gel formulation is safe to use as a topical formulation. The comparison of FT-IR spectrum study of herbal gel and methanol extract confirmed no any extract-excipients interaction. The excipients were found compatible with methanol extract Figure 2 and 3. In-vitro diffusion study of Cordia obliqua topical gel through cellophane membrane has shown that cumulative \% drug release of the gel was $43 \%$ after $6 \mathrm{~h}$ and it was increasing with time Table 4, Figure 4. The diffusion of gel can be more increased with addition of penetration enhancers.

Table 1: Gel composition for $100 \mathrm{~g}$ of Cordia obliqua topical gel.

\begin{tabular}{ccc}
\hline S. No. & Drug/Chemical name & Amount \\
\hline 1 & Cordia obliqua leaf methanol extract & $5 \mathrm{~g}(5 \%)$ \\
2 & Carbopol 940 & $1 \mathrm{~g}(1 \%)$ \\
3 & Methyl Paraben & $0.2 \mathrm{ml}(0.5 \%)$ \\
4 & Propyl Paraben & $0.1 \mathrm{ml}(0.2 \%)$ \\
5 & Propylene Glycol 400 & $5 \mathrm{ml}(5 \%)$ \\
6 & Triethanolamine (TEA) & q.s. $(1.2 \mathrm{ml})$ \\
7 & Water & Up to $100 \mathrm{ml}$ \\
\hline
\end{tabular}

Table 2: Evaluation parameters for Cordia obliqua leaf methanol extract topical gel.

\begin{tabular}{ccc}
\hline S. No. & Evaluation parameter & Observation \\
\hline 1. & Gel appearance & Light Green \\
2. & Homogeneity & Good \\
3. & Grittiness & Absent \\
4. & Extrudability & Good $(70.63 \%)$ \\
5. & Viscosity & $36477 \pm 716 \mathrm{cps}$ \\
6. & $\mathrm{pH}$ & $6.79 \pm 0.02$ \\
7. & Spread ability & $3.8 \pm 0.36 \mathrm{~cm}$ \\
8. & Drug content & $93.167 \%$ \\
9. & Skin irritation & None observed (Score $=0)$ \\
10. & Cumulative drug release & $43 \%$ \\
\hline
\end{tabular}

Table 3: Preparation of standard curve for Cordia obliqua leaf methanol extract.

\begin{tabular}{ccc}
\hline S. No. & Extract concentration $(\mu \mathrm{g} / \mathrm{ml})$ & Absorbance at $275.5 \mathrm{~nm}$ \\
\hline 1 & 50 & 0.212 \\
2 & 100 & 0.381 \\
3 & 150 & 0.564 \\
4 & 200 & 0.735 \\
5 & 250 & 0.910 \\
6 & 300 & 1.036 \\
\hline
\end{tabular}

Table 4: In-vitro diffusion study of Cordia obliqua topical gel.

\begin{tabular}{ccc}
\hline S. No. & Time in $\mathbf{~}$ & Cumulative \% drug release \\
\hline 1 & 0 & 0 \\
2 & 1 & 23.28719 \\
3 & 2 & 28.43057 \\
4 & 3 & 31.25995 \\
5 & 4 & 36.40333 \\
6 & 5 & 38.60162 \\
7 & 6 & 43.00873 \\
\hline
\end{tabular}




\section{Evaluation of anti-inflammatory activity of topical gel formulation}

The effect of Cordia obliqua Willd. leaf methanol extract gel formulation on Carrageenan induced paw edema in rats were shown in Table 5 and Figure 5.

The herbal gel formulation has significantly inhibited edema up to $82.71 \%$. The positive control group was compared with standard i.e. Diclofenac Sodium gel 1.0\% and gel formulation of Cordia obliqua Willd. leaf methanol extract. As per statistical analysis, the herbal test gel has been shown highly significant $(\mathrm{p}<0.001)$ effect after $3 \mathrm{~h}$ of drug adminis- tration and the standard gel has shown highly significant $(\mathrm{p}<0.001)$ effect after $2 \mathrm{~h}$ of drug administration.

\section{DISCUSSION}

Gels are the semi-solid system of drug delivery and constitute a well reputation among various pharmaceutical dosage forms. Now a day, herbal gels are becoming popular due to their safe and effective use. So, the study was designed to formulate topical gel of Cordia obliqua plant leaf methanol extract. This plant leaf methanol extract was found rich in various Phyto-constituents with good effect in treatment of pain, fever

Table 5: Effect of Cordia obliqua topical gel on Carrageenan Induced Paw Edema in rats.

\begin{tabular}{ccccccc}
\hline \multirow{2}{*}{ Group/Drug } & \multicolumn{5}{c}{ Paw size in mm at time in h $(\mathbf{h})$} \\
\cline { 2 - 7 } & Before $1 \mathrm{~h}$ & $\mathbf{0 ~ h}$ & $1 \mathrm{~h}$ & $2 \mathrm{~h}$ & $3 \mathrm{~h}$ & $4 \mathrm{~h}$ \\
\hline Positive control / Gel base & $3.93 \pm 0.09$ & $3.97 \pm 0.2$ & $5.27 \pm 0.14$ & $5.61 \pm 0.11$ & $5.68 \pm 0.12$ & $5.26 \pm 0.18$ \\
& & & $4.63 \pm 0.15^{* *}$ & $4.47 \pm 0.10^{* * *}$ & $4.03 \pm 0.01^{* * *}$ & $3.68 \pm 0.14^{* * *}$ \\
Standard / Diclofenac Sodium Gel & $3.55 \pm 0.17$ & $3.73 \pm 0.11$ & $(19.36 \%)$ & $(45.23 \%)$ & $(72.57 \%)$ & $(90.22 \%)$ \\
& & & $5.06 \pm 0.14$ & $5.03 \pm 0.13^{*}$ & $4.38 \pm 0.01^{* * *}$ & $4.11 \pm 0.07^{* * *}$ \\
Test / Herbal gel & $3.88 \pm 0.15$ & $3.91 \pm 0.12$ & $(11.94 \%)$ & $(31.55 \%)$ & $(71.42 \%)$ & $(82.71 \%)$ \\
\hline
\end{tabular}

Each column represents the mean \pm S.E.M. for $\mathrm{n}=6 .{ }^{*}(p<0.05),{ }^{* *}(p<0.01),{ }^{* * *}(p<0.001)$ values compared with positive control and considered as significant, more significant, highly significant respectively. Data analyzed by One-way ANOVA followed by Tukey's Test.

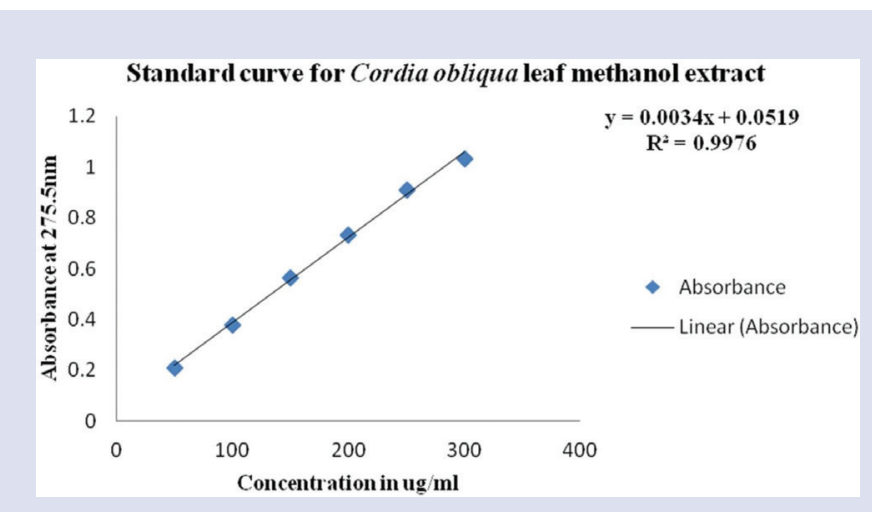

Figure 1: Determination of drug content in Cordia obliqua topical gel.

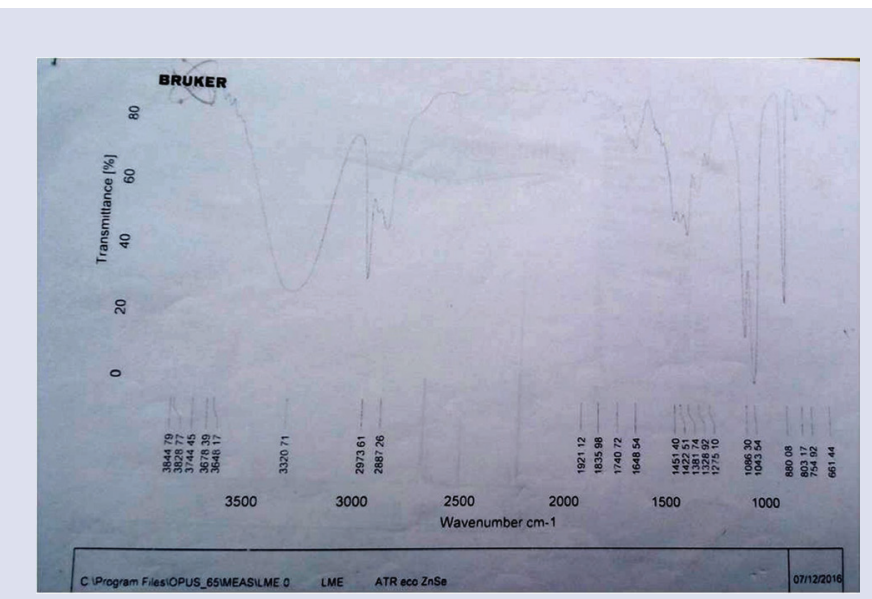

Figure 2: FT-IR spectra of Cordia obliqua leaf methanol extract.

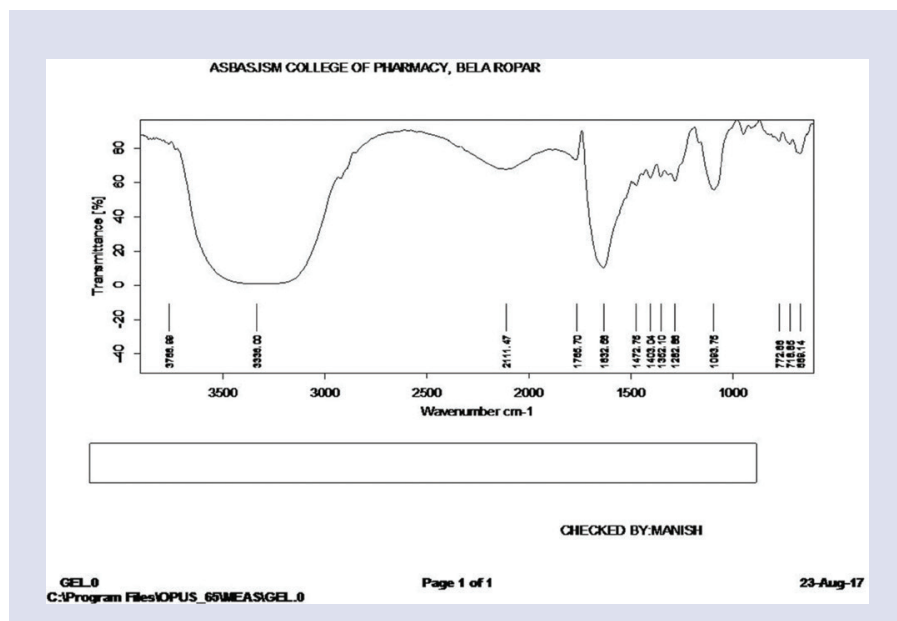

Figure 3: FT-IR spectra of Cordia obliqua topical gel formulation.

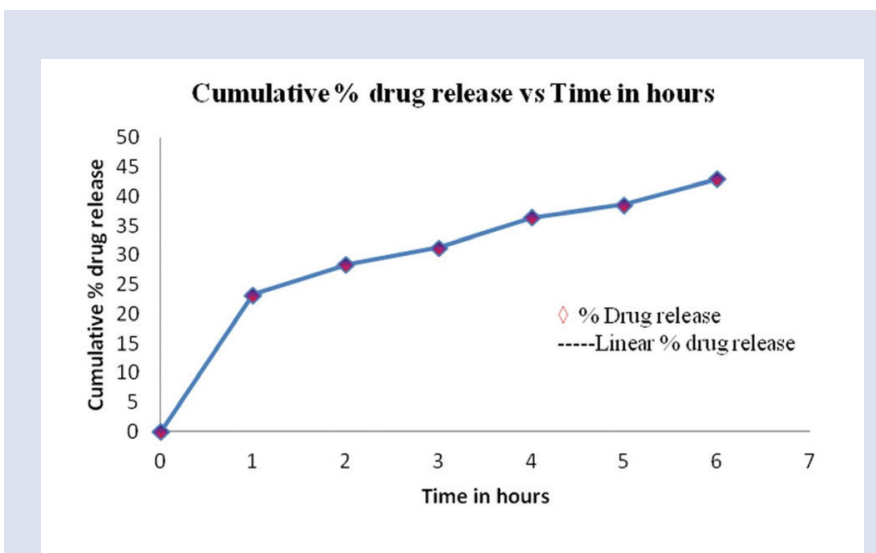

Figure 4: In-vitro diffusion study of Cordia obliqua topical gel. 


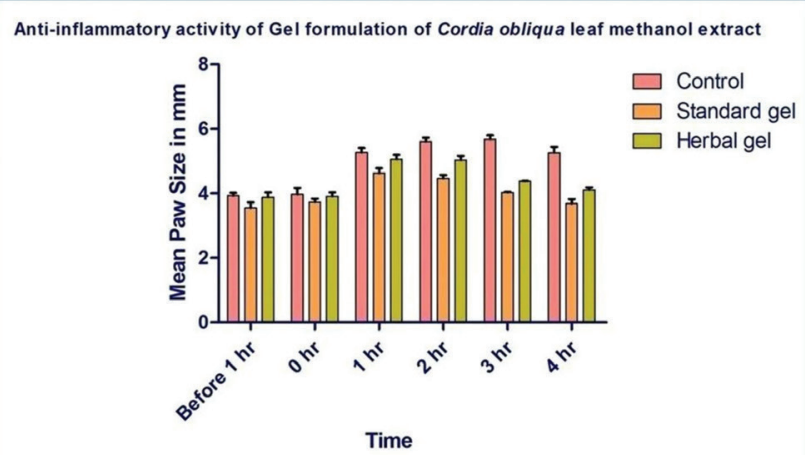

Figure 5: Anti-inflammatory activity study of Cordia obliqua topical gel.

and inflammation as per our previous studies. The formula was developed for $100 \mathrm{~g}$ of gel containing $5 \mathrm{~g}$ of leaf extract. Other constituents were polymer Carbopol 940 (Gelling agent), Propyl Paraben and Methyl Paraben (Preservatives), Propylene Glycol 400 (Lubricant), Triethanolamine/TEA (pH and buffer adjusting agent) and water (Vehicle). ${ }^{22,23} \mathrm{Gel}$ was prepared by Dispersion method. Various physico-chemical parameters of gel were studied and the herbal gel was found light green in color, homogeneous, smooth, easily spreadable, with good extrudability and $\mathrm{pH}$ near to normal skin $\mathrm{pH}$ range. No any skin irritation was observed due to gel application for seven days of study. No any particulate matter was seen in gel under light microscope. The drug content in gel was determined $93.167 \%$ and in-vitro diffusion study through Cellophane membrane has shown $43 \%$ cumulative drug release after $6 \mathrm{~h}$ and it was increasing with time. The drug release can be improved by using penetration enhancers. Hence the gel preparation fulfils the entire requirements as desired for any topical formulation.

After evaluation of gel characteristics, anti-inflammatory activity by carrageenan induced rat paw edema method was also studied for herbal gel. Carrageenan cause acute inflammation and it is a well-established method for anti-inflammatory study. The effect of herbal gel was compared with effect of standard Diclofenac Sodium gel (1\%) on rat paw edema. The herbal gel has shown its effect after $3 \mathrm{~h}$ of treatment i.e. late phase edema ${ }^{24,25}$ and maximum $82.71 \%$ of edema inhibition was found after $4 \mathrm{~h}$ of treatment. So, the herbal gel effect was found comparable with standard Diclofenac gel.

From all these studies we can finally state that Cordia obliqua topical gel is an influential composition because it has shown all required parameters for a topical formulation with none skin irritation and easiness in use. As it is an herbal gel, so decreases the chances of side effects also. Along with these specifications, it has shown good comparable antiinflammatory effect with standard Diclofenac Sodium gel.

\section{CONCLUSION}

It can be concluded that Cordia obliqua Willd. leaf methanol extract topical gel is an ideal and effective formulation. It can be used safely for treatment of inflammatory conditions. This study also supports the activities of this plant leaf methanol extract for treatment of pain, inflammation and pyrexia. Further, determination of exact mechanism of action and lead active constituent for anti-inflammatory activity of Cordia obliqua gel will be the new target of study.

\section{ACKNOWLEDGEMENT}

The authors express their sincere thanks to faculty and management of ASBASJSM College of Pharmcay, Bela (Ropar). We are also grateful to IK Gujral Punjab Technical University, Jalandhar for all assistance provided.

\section{CONFLICT OF INTEREST}

The authors have no any conflict of interest.

\section{ABBREVIATION USED}

SEM: Standard Error Mean; rpm: rate per minute; BW: Body Weight; ANOVA: Analysis of Variance; CPCSEA: Committee for the Purpose of Control and Supervision of Experiments on Animals.

\section{REFERENCES}

1. Kaur LP, Guleri TK. Topical Gel: A recent approach for novel drug delivery. Asian J Biomed Pharm Sci. 2013;3(17):1-5.

2. Gupta R, Gupta GD. A review on plant Cordia obliqua Willd. (Clammy Cherry). Pharmacognosy Rev. 2015;9(18):127-31.

3. Gupta R, Gupta GD. Pharmacognostic, phytochemical and antioxidant studies on Cordia obliqua Willd. leaf. Inter J Pharm Sci Res. 2016;7(11):4669-76.

4. Gupta R, Gupta GD. Toxicity assessment and evaluation of analgesic, antipyretic and anti-inflammatory activities on Cordia obliqua leaf methanol extract. Pharmacognosy J. 2017;9(6):856-61.

5. Helal DA, El-rhman DA, Abdel-halim SA, El-nabarawi MA. Formulation and evaluation of Fluconazole topical gel. Inter J Pharm Pharma Sci. 2012;4(5):176-83.

6. Kaur P, Kaur L, Khan MU. Topical formulations and Hydro-gel: An overview. Inter J Adv Pharm Biology Chem. 2013;2(1):201-6.

7. Mohammed HKP, Mohanta GP, Nayar C. Formulation and evaluation of herbal gel of Basella alba for wound healing activity. J Pharm Sci Res. 2012;4(1):1642-8.

8. Khan AW, Kotta S, Ansari SH, Sharma RK, Kumar A, Ali J. Formulation development, optimization and evaluation of Aloe Vera gel for wound healing. Pharmacognosy Mag. 2013;9(1):S6-S10.

9. Liberman HA, Reiger MM, Banker GS. Pharmaceutical dosage forms: disperse system; New York: 1989:594-8.

10. Chakole CM, Shende MA, Khadatkar SN. Formulation and development of novel combined halobetasol propionate and fusidic acid ointment. Inter $\mathrm{J}$ Chem Tech Res. 2009; 1(1):103-16.

11. Gupta GD, Gaud RS. Release rate of Nimesulide from different gellants. Indian J Pharm Sci. 1999;61(4):227-30.

12. Shivhare UD, Jain KB, Mathur VB, Bhusari KP, Roy AA. Formulation, development and evaluation of Diclofenac Sodium gel using water soluble polyacrylamide polymer. Dig J Nanomaterials and Bios. 2009;4(2):285-290.

13. Joshi M, Patravale V. Formulation and evaluation of Nanostructured lipid carrier (NLC)- based gel of Valdecoxib. Drug Dev Industrial Pharm. 2006;32(8):911-8.

14. Kumar L, Verma R. In-vitro evaluation of topical gel prepared using natural polymer. Inter J Drug Delivery. 2010;2(1):58-63.

15. Misal G, Dixit G, Gulkari V. Formulation and evaluation of herbal gel. Indian J Nat Prod Resources. 2012;3(4):501-5.

16. Kumar S, Balaji A. Formulation and evaluation of Transfersomal Gel of Sumatriptan Succinate. Indo American J Pharm Res. 2015:5(11):3426-38.

17. Swetha $\mathrm{CH}$, Velmurugun S, Raju PN, Reddy GN. Formulation and evaluation of Clarithromycin topical gel. Inter J Drug Dev and Res. 2013;5(4):194-202.

18. Singh B, Kaur T, Singh S. Correction of raw dissolution data for loss of drug and volume during sampling. Indian J Pharm Sci. 1997;59(4):196-9

19. Chatterjee A, Bhowmik BB, Thakur YS. Formulation, in-vitro and in-vivo Pharmacokinetics of Anti-HIV vaginal bio-adhesive gel. J Young Pharmacists. 2011; $3(2): 83-9$.

20. Khullar R, Kumar D, Seth N, Saini S. Formulation and evaluation of mefenamic acid emulgel for topical delivery. Saudi Pharm J. 2012;20(1):63-7.

21. Gupta R, Kaur J. Evaluation of analgesic, antipyretic and anti-inflammatory activity on Cordia dichotoma G. Forst. Leaf. Pharmacognosy Res. 2015;7(1):126-30

22. Viswanad V, Aleykutti NA, Jayakar B, Zacharia SM, Thomas L. Development and evaluation of antimicrobial herbal formulations containing the methanolic extract of Samadera indica for skin diseases. J Adv Pharm Technology Res. 2012;3(2):106-111.

23. Jaiswal NR, Jaiswal PH, Patil JK. Formulation and evaluation of topical antibacterial herbal gel of Coriander and Eucalyptus oil. World J Pharm Pharma Sci. 2014;3(7):774-86.

24. Maity TK, Manda, SC, Mukherjee PK, Saha K, Pal M, Saha B. Studies on antiinflammatory effect of Cassia tora leaf extract (fam. Leguminosae). Phyto therapy Res. 1998;12(3):221-3.

25. Perez-Guerreo C, Herrera MD, Ortiz R, Alvarez-de SM, Fernandez MA A pharmacological study of Cecropia obtusifolia Bertol aqueous extract. J Ethnopharmacology. 2001;76(3):279-84. 
GRAPHICAL ABSTRACT

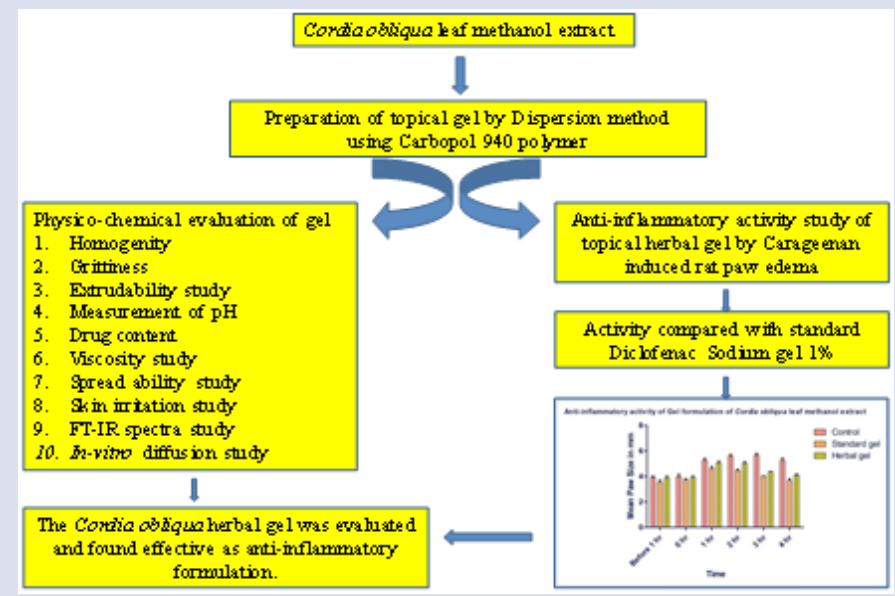

\section{SUMMARY}

- Cordia obliqua leaf methanol extract was selected for topical gel formulation.

- The herbal gel was prepared by Dispersion method using Carbopol 940 as polymer.

- The gel was evaluated for various physico-chemical parameters like Homogeneity, grittiness, determination of $\mathrm{pH}$, skin irritation, Drug content, FT-IR study, extrudability study, spread ability study and in-vitro diffusion study.

- The anti-inflammatory potential of herbal gel was also evaluated using Carrageenan induced rat paw edema and compared with standard Diclofenac Sodium gel 1\%.

- The Cordia obliqua topical gel was standardized and found effective as an anti-inflammatory gel formulation.

\section{ABOUT AUTHORS}

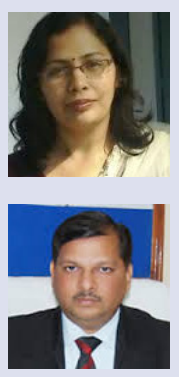

Richa Gupta: PhD scholar at IK Gujral Punjab Technical University, Jalandhar and Assistant Professor at ASBASJSM College of Pharmacy, Bela, Ropar, Punjab. Work experience is 10 years.

Prof. (Dr.) Ghanshyam Das Gupta: Director ISF College of Pharmacy, Moga, Punjab. Work experience is more than 20 years.

Cite this article: Gupta R, Gupta GD. Formulation Development and Evaluation of Anti-inflammatory Potential of Cordia obliqua Topical Gel on Animal Model. Pharmacog J. 2017;9(6)Suppl:s93-s8. 